Article

\title{
Bridging Theories and Practices: Boundary Objects and Constellation Analysis as Vehicles for Interdisciplinary Knowledge Integration
}

\author{
Berenike Feldhoff ${ }^{1, *}$, Nils Stockmann ${ }^{1}$, Nora Fanderl ${ }^{2}$, Anne-Kathrin Gahle ${ }^{3}$, Antonia Graf ${ }^{1}$, \\ Matthias Leger ${ }^{4}$ and Marco Sonnberger ${ }^{4}($ ) \\ 1 Institute of Political Science, University of Muenster, 48151 Muenster, Germany; \\ nils.stockmann@uni-muenster.de (N.S.); antonia.graf@uni-muenster.de (A.G.) \\ 2 Fraunhofer Institute for Industrial Engineering IAO, 70569 Stuttgart, Germany; \\ Nora.Fanderl@iao.fraunhofer.de \\ 3 Institute of Human Factors and Technology Management IAT, University of Stuttgart, \\ 70569 Stuttgart, Germany; Anne-Kathrin.Gahle@iao.fraunhofer.de \\ 4 Stuttgart Research Center for Interdisciplinary Risk and Innovation Studies (ZIRIUS), University of Stuttgart, \\ 70174 Stuttgart, Germany; matthias.leger@zirius.uni-stuttgart.de (M.L.); \\ marco.sonnberger@zirius.uni-stuttgart.de (M.S.) \\ * Correspondence: berenike.feldhoff@uni-muenster.de
}

Received: 25 July 2019; Accepted: 25 September 2019; Published: 27 September 2019

check for updates

\begin{abstract}
Knowledge integration is a major challenge of interdisciplinary research. Substantially different stocks of knowledge based on different scientific backgrounds, uses of language, methodologies, and epistemologies must be integrated into the research process. Addressing this challenge, this paper exemplifies the process of interdisciplinary knowledge integration drawing on the example of the junior research group DynaMo-Mobility-Energy Dynamics in Urban Areas that deals with the sustainable transformation of urban mobility systems. This paper shows how we apply the boundary object concept in combination with the method of Constellation Analysis as vehicles for interdisciplinary knowledge integration. By innovatively combining the boundary object concept with Constellation Analysis we (a) suggest a self-reflective tool for structuring the process of knowledge integration and (b) further operationalize the boundary object with the help of core concepts. The approach is illustrated with the boundary object sustainable transformation of urban passenger mobility used by DynaMo. In doing so, the paper aims to add an instrument to the toolkit of inter- and transdisciplinary research and offers practical knowledge for its application.
\end{abstract}

Keywords: interdisciplinarity; knowledge integration; transdisciplinary research; boundary objects; constellation analysis; sustainable urban mobility

\section{Introduction}

Against the background of the increasingly complex socio-ecological and related socio-technical challenges our societies are facing (e.g., anthropogenic climate change, biodiversity loss, energy and mobility transitions, etc.), inter- and transdisciplinary research are gaining importance due to their (hoped for) capacity of providing knowledge for handling these challenges and identifying viable solutions. Interdisciplinary studies incorporate cooperation between different scientific disciplines in order to develop knowledge which transcends the boundaries of singular disciplines [1] (p. 9). Transdisciplinarity is understood as an "integrative research approach" [2] (p. 379) that adds cooperation between researchers and practitioners to the inner-scientific cooperation between various disciplines [3] (p. 2). 
The key challenge of inter- and transdisciplinary research is knowledge integration [4] (p. 41). While knowledge integration is seen as crucial to inter- and transdisciplinary cooperation, it is also considered a complex and critical endeavor. Knowledge integration should be more than just adding up disciplinary findings and instead should mean the combination of heterogeneous knowledge stocks with the aim of creating an identifiable synthesis product and new insights that go beyond putting different findings side by side [4] (p. 41). The focus of this paper is on interdisciplinary knowledge integration which is often the starting point as well as a continuous process in inter- and transdisciplinary research projects. The challenges of interdisciplinary knowledge integration stem from the fact that diverse, substantially different stocks of disciplinary knowledge must be brought together in the research process. These are based on an individual and disciplinary use of language, diverse scientific understandings (epistemologies and methodologies), or different career stages of the involved researchers and contain various points of view and potentially diverging preferences. In order to meet these challenges and achieve understanding between diverse actors with different scientific backgrounds and traditions of thought, it is necessary to create a common frame of reference [5] (p. 184). Depending on how closely the respective disciplines are aligned in their use of certain theories, methods and paradigms, knowledge integration can take various forms. Importantly though, the different scientific disciplines must jointly develop and work on research questions that all involved disciplines can methodically and empirically address [6].

The present article addresses and illustrates the challenges of interdisciplinary knowledge integration using the example of a framework of knowledge integration developed by the junior research group DynaMo - Mobility-Energy Dynamics in Urban Areas. DynaMo deals with the complex issue of the sustainable transformation of urban mobility systems. Since mobility systems can be regarded as a socio-technical constellation, interdisciplinary perspectives on mobility-related issues build an essential basis for developing solutions. DynaMo unites seven researchers from sociology, political science, and urban planning. The junior research group is funded from 2016 to 2021 by the German Federal Ministry of Education and Research (BMBF). Junior research groups are a specific funding format within Social-Ecological Research funding priority, which aims are explicated in the following: "Young researchers shall receive the opportunity to further qualify in the interlinked fields of natural sciences, engineering and social sciences [ ... ]. While working on a self-chosen topic, the junior research groups are encouraged to focus-beyond the research results themselves-on developing and cultivating an interdisciplinary research culture" [7]. In two habilitation projects and five dissertation projects, DynaMo investigates current change processes and future change potentials (dynamics) in the field of urban mobility. The focus is on socio-technical innovations and developments in the field of urban passenger mobility. In addition, the research project pursues the overarching transdisciplinary aim of developing recommendations for action for the more sustainable design of urban mobility systems.

Whereas the overarching topic of the junior research group Mobility-Energy Dynamics in Urban Areas was set from the beginning, the question arose of how to integrate the knowledge and perspectives of researchers from the different disciplines involved. DynaMo strives to achieve this through research work on a common boundary object [8]. In this paper, we offer an example of how to apply Susan Star's and James Griesemer's boundary object concept [8] as well as the method of Constellation Analysis [9] as vehicles for interdisciplinary knowledge integration in a transdisciplinary research project. In a new, comprehensive framework, we (a) innovatively combine the boundary object concept with Constellation Analysis as self-reflective tools for structuring the process of knowledge integration and (b) incorporate the notion of core concepts to further operationalize the boundary object and to facilitate communication among disciplines. Our framework enables research groups to work together on joint objectives while the group members maintain their own identities and cognitive orientations as researchers of different disciplines.

In part 2 of the paper, we elaborate first on the conceptual roots of the boundary object concept and Constellation Analysis and second on the virtues of combining both concepts. In part 3, 
we illustrate the framework with the example of the boundary object 'sustainable transformation of urban passenger mobility' developed by the junior research group DynaMo. The core concepts applied in this example - participation, legitimacy, space, governance, mobility practices, and power-provide references for (theoretical) discussions and knowledge integration within the group, as illustrated in that section. Based on our practical experiences within the context of the junior research group, part 4 shows how, through the method of Constellation Analysis, these core concepts can be situated, developed, and advanced. In part 5, we critically discuss our approach and draw some general conclusions on the framework's contributions to the toolkit of interdisciplinary knowledge integration as well as its limitations.

\section{Roots of Concepts: Boundary Objects and Constellation Analysis as Vehicles for Knowledge Integration}

\subsection{Boundary Objects}

The theoretical concept of boundary objects has its roots in the field of science and technology studies (STS). In their seminal article "Institutional Ecology, "Translations" and Boundary Objects: Amateurs and Professionals in Berkeley's Museum of Vertebrate Zoology", published in 1989, Susan Star and James Griesemer examined how scientific cooperation between different actors (amateurs, professionals, administrators, etc.) evolved and stabilized in the early years of the Museum of Vertebrate Zoology at the University of California, Berkeley [8]. The starting point for the elaboration of the concept was the crucial question of how actors rooted in different social worlds can coordinate and cooperate despite diverging perspectives. Susan Star and James Griesemer's basic observation was that "consensus is not necessary for cooperation nor for the successful conduct of work" [8] (p. 388). Difficulties in (scientific) cooperation between different actors mainly emerge because objects and methods have different meanings in different worlds. Thus, these different meanings have to be reconciled for cooperation [8] (pp. 388-389). Susan Star and James Griesemer showed that collaboration between the different actors in the Museum of Vertebrate Zoology, i.e., between different social worlds, became possible because they focused on common boundary objects such as ideal types or standardized methods that allowed for collaboration in the absence of consensus [10] (p. 604). Thus, boundary objects are objects—not necessarily in a material sense—-that build the center of work-related cooperation between different groups. By drawing on a common boundary object, the associations between information, practices, and actors emerge and stabilize despite the tension between cooperation and heterogeneity [11].

From its origins in 1989 to this date, the boundary object concept has been adopted by scholars in many different fields, such as policy analysis [12], organization theory [13], sociology of science [14], etc. (for a comprehensive overview please see: [11]). It has also been adopted in the field transdisciplinary research, which is somewhat unsurprising because this field is particularly based on the tension between different perspectives, interests, knowledge forms, and the need for cooperation and knowledge integration [15].

Susan Star and James Griesemer define their boundary object concept as follows: "Boundary objects are objects which are both plastic enough to adapt to local needs and the constraints of the several parties employing them, yet robust enough to maintain a common identity across sites. They are weakly structured in common use and become strongly structured in individual-site use. These objects may be abstract or concrete. They have different meanings in different social worlds but their structure is common enough to more than one world to make them recognizable, a means of translation. The creation and management of boundary objects is a key process in developing and maintaining coherence across intersecting social worlds" [8] (p. 393). According to Susan Star, there are no rules for classifying what counts as a boundary object. This always depends on the specific context [10]. In the field of transdisciplinary research such diverse objects as scenarios (e.g., scenarios for the development of renewable energies), models (e.g., climate models), interdisciplinary frameworks and concepts (e.g., ecosystem services framework or biodiversity), spatial foci (e.g., case studies in a specific city 
or region), among others, are considered and applied as boundary objects [3,15]. This diversity of what is applied as boundary objects already points to a critical shortcoming of the boundary object concept as a theoretical basis for structuring processes of knowledge integration in interdisciplinary settings: the boundary object concept has been criticized as being vague and fuzzy in its definition what actually could count as a boundary object and what not [10]. However, since we primarily apply the boundary object concept as a theoretical guideline of how to deal with a real-world problem as a common focus point for interdisciplinary research, the theoretical question about the actual nature of boundary objects is only of secondary relevance for us.

In order to give a more comprehensive idea of what a boundary object is and how one is used in cooperation, it is useful to take a closer look at three crucial features of a boundary object [10]:

- Interpretive flexibility: Boundary objects are open to different interpretations. Although they have different meanings for different actors, these meanings are sufficiently structured to be recognized by others. Thus, a boundary object enables diverse groups (in the context of transdisciplinary research, e.g., researchers from different disciplines, stakeholders, citizens, etc.) to share knowledge and to cooperate without demanding substantive agreement upon the very nature of the boundary object, i.e., the integrative object of cooperation $[10,11,16,17]$. Thus, the definition and understanding of the boundary object, on which the collaboration in an interdisciplinary research group is based (e.g., services of a certain river as an aquatic ecosystem), should not be too narrow in order to enable all participating researchers (in a transdisciplinary setting also stakeholders and practitioners) to make sense of it on basis of their disciplinary backgrounds. Otherwise, some researchers would be excluded from the process of knowledge production and integration.

- Organizational structure: The term 'boundary' describes a shared space of meaning that demarcates and contains an 'object' that people act toward and with. This is not necessarily a physical/material object. In this regard, a theory can also be an object [10]. I.e., as already mentioned above, a broad range of things can serve as boundary objects. Thereby, boundary objects can be both rather abstract such as the concept of biodiversity and quite concrete such as a map of a specific nature conservation area [3].

- Dynamic between ill-structured and more tailored uses of the objects: In the process of cooperation, actors tack back and forth between specific and narrow uses and meanings in one social world and more vague meanings and uses across social worlds. With regard to interdisciplinary research collaborations this means that in a disciplinary context researchers would interpret and work with the boundary object (e.g., ecosystem services framework) in an very specific way (e.g., writing an sociological article on cultural ecosystem services as an element of nature-society relations), while in the interdisciplinary context the boundary object would be interpreted and treated in a less specific way in order to enable interdisciplinary cooperation (e.g., developing policy recommendations for the protection of a certain aquatic ecosystem going beyond the narrow focus on, for example, cultural ecosystem services). If the back and forth stop, the boundary object loses its boundary-spanning function and thus can no longer function as an integrative tool, because it has either become too general and vague or to narrow and specific, i.e., accustomed to only one social world $[10,16,17]$. This would, for example, be the case when in an interdisciplinary research collaboration one discipline imposes its discipline-specific interpretation of the boundary object (e.g., ecosystem services as a social construction) as mandatory for the whole research group. Then the other disciplines would not be able to work on the boundary object in their discipline-specific way anymore and cooperation would fail.

As a tool for cooperation, a boundary object facilitates dialogue between different actors and allows for different practices referring to the boundary object. Furthermore, different aspects of the object can serve as a basis for dialogue between different actors [11,18]. In the process of cooperation, a boundary object can be deliberately defined and actively maintained. In this regard, Paul Carlile 
emphasizes that an effective boundary object should establish a shared language so that the different cooperating actors can represent their knowledge, enable the different cooperating actors to learn about their differences and dependencies and facilitate a common process of knowledge transformation and integration [13] (pp. 451-452).

\subsection{Constellation Analysis}

Constellation Analysis has its origins in the early 2000s and was developed at the Center for Technology and Society at the Technical University Berlin [19]. Also based on an STS perspective, Susanne Schön and colleagues developed Constellation Analyses as a way to strategically integrate knowledge in the context of inter- and transdisciplinary research projects, specifically regarding technology, sustainability, and innovations. Constellation Analysis can be described "as a methodological approach of innovation research which aims at understanding highly complex processes of invention and diffusion" [9] (p. 258). As a "bridging concept" it offers a way of "comprising several analytical categories which different disciplines can relate to" [20] (p. 119). In the context of the DynaMo project, this function of Constellation Analysis allows for its use as a self-reflective tool that helps to understand the evolution of the project from the different disciplinary perspectives. Thereby, Constellation Analysis helps to "preserve the disciplinary particularities while bridging the scientific cultures" [9] (p. 261) of the research group members.

Schön and colleagues describe constellations as sets of heterogeneous elements that characterize and constitute a scientific and/or social problem. Constellations do contain a certain degree of order, which comes from the relations between the actors and elements given. The purpose of performing a Constellation Analysis is to understand innovation processes by integrating different disciplinary perspectives and knowledge levels [19] (p. 9).

The Constellation Analysis approach involves two major considerations that constitute the core of Constellation Analysis. The first point, which is that the different elements are looked at as equal entities, goes back to early actor-network theory [21] and "allows [for] a non-hierarchical interdisciplinary cooperation which does not differentiate in terms of 'leading' and 'auxiliary disciplines'" [20] (p. 120). This means that, for example, in the case of biodiversity, biological elements such as a river in a certain industrial area as well as species protection as a societal value, are regarded as equal and co-constitutive. Through their relations with other elements such as chemical waste and contamination, they form the constellation that builds the basis for interdisciplinary cooperation where neither biologists nor sociologists have a predominant position in the research process. Furthermore, this conception does not make analytical differences between social, cultural, or technical aspects. In doing so, it fundamentally challenges the perspective that technical elements are the primary drivers of change. The second point is the approach's bottom-up character, which Ohlhorst and Schön describe as similar to the Grounded Theory Methodology [9] (pp. 259,272). Thus, this analytical perspective "does justice to the respective individual course of innovation processes" [9] (p. 259) and has its foundation in the field rather than in preexisting conceptions.

As a comprehensive framework, Constellation Analysis allows for two variants of research on socio-technical issues. Throughout "the retrospective study of the constellations" [9] (p. 260) surrounding a sociotechnical phenomenon, process, fact, etc. [9], it is possible to look at an already established innovation (e.g., Red List of Threatened Species) and reconstruct its course with a close look to the involved elements and their specific relations and interactions (regulatory authorities, biologists, labs, federal administrations). Based on an understanding of this 'evolution', the determined knowledge can be re-integrated in policy-making processes or recommendations. The second variant is the identification of possible future trajectories of socio-technical processes that are still evolving. The authors call that the "strategic analysis perspective" [9] (p. 260) where, from a given status quo (e.g., a specific fragile ecosystem), the research team tries to identify possible future developments towards desirable innovations (protection by establishing an expert commission, necessary collaborations between actors, defining sets of measures, etc.). 
Methodically, Constellation Analysis uses a set of specific terms to integrate these perspectives and enable common understanding. The approach distinguishes four types of elements (actors, technical elements, symbolic elements, and natural elements) as well as different types of relations between those elements (e.g., simple, directed, missing, or conflictual relations). Using these terms, Constellation Analysis offers three consecutive steps of analysis that should ideally be carried out in a cyclical process. It is important to see this mapping process as a communicative process of negotiation within the research team.

In the first step, the team maps the constellation by identifying the different elements that "characterize the particular problem" [9] (p. 263). This includes the arrangement and description of the different relations among those elements (e.g., conflictual relations between a regulatory authority and citizens' initiatives). The research team then works out the functional principles and characteristics of the constructed constellation in a second step [9] (p. 264). This step addresses questions concerning special or dominant actors, hidden alliances, or power relations, which means that the analysis is lifted up on a more conceptual level, following the more descriptive relations among the elements. The final step addresses the dynamics of the constellation and seeks for "the processes of change that affect or could affect the constellation" [9] (p. 265). (e.g., the implementation of a regulation). Section 4 illustrates this process in the context of DynaMo.

Its explicit orientation towards interdisciplinary research makes Constellation Analysis suitable for different scientific disciplines as well as for practitioners. With its straightforward analytical procedures, it functions as a "method that builds upon disciplinary findings, which it shakes up in an interdisciplinary fashion" and which "can then be reintegrated into the existing disciplinary specific theory, as well as into technical and political concepts" [9] (p. 271). Through the alternation of mapping and textual interpretations of the constellation, the approach offers a possibility of establishing a common language by discourse and negotiation [9] (p. 272). As some kind of "bridging concept" [9] (p. 273), Constellation Analysis thus offers a methodical equivalent to the rather theoretically driven boundary object concept as described above.

\subsection{The Virtues of Combining the Boundary Object Concept and Constellation Analysis}

The fact that "Constellation Analysis has no particular obligation to any one theory or discipline, but is instead oriented toward the object of study and the question at hand" [9] (p. 272) makes it easily accessible for inter- and transdisciplinary research. This underlines its usefulness as a 'bridging concept' that enables groups to integrate the heterogeneous perspectives of different academic disciplines [19,20]. With its aim of generating "access to a scientific object from different perspectives" [9] (p. 258), Constellation Analysis shares a common ground with the formulation of a boundary object, as shown above. Both the boundary object concept and Constellation Analysis are grounded in a methodological symmetry between material and biophysical factors on the one hand and social factors on the other [22]. Thus, when working in an interdisciplinary setting, deliberately applying the boundary object concept and Constellation Analysis allows for an equitable interdisciplinary knowledge integration without privileging insights of one discipline over those of another. Furthermore, since both boundary object concept and Constellation Analysis are grounded in theoretical considerations, they offer a conceptual basis for the joint identification of a research objective and its elaboration and operationalization. In the context of the research group DynaMo, boundary object concept and Constellation Analysis can thus be regarded as 'self-reflective tools' that help to understand and structure the process of knowledge integration. Moreover, both concepts fulfill a sensitizing function by warning of pitfalls in processes of interdisciplinary knowledge integration (e.g., too narrow and discipline-specific definition of joint research objectives). Of course, the whole process of identifying an interdisciplinary research objective and jointly working toward achieving it can also be designed and run through intuitively without making its different aspects, elements, and steps explicit. However, since knowledge integration is the crucial issue of inter- and transdisciplinary research [23], we would argue for doing this as deliberately as possible. Both boundary object concept and Constellation 
Analysis can thereby be of help as 'self-reflective tools' as we are aiming to illustrate in this paper. Thus, we understand the application of the boundary object concept and the Constellation Analysis as a means through which fruitful collaboration can be achieved and not as a research puzzle per se or as methods for solving research puzzles.

While, as mentioned above, both the boundary object concept and Constellation Analysis each have been applied in inter- and transdisciplinary research as tools for facilitating knowledge integration, to our knowledge they have not yet been applied in combination. By looking at boundary objects as a specific type of constellation [1], the analytical vocabulary of Constellation Analysis allows us to work out different dimensions of the boundary object more precisely and to offer a deep description from each disciplinary perspective. Furthermore, to deepen and systematize the elaboration of a boundary object in an interdisciplinary setting, we suggest operationalizing the boundary object concept through what we call core concepts. These will be further exemplified in the next section. With the combination of both the boundary object approach (specified by core concepts) and Constellation Analysis, we aim to offer a systematic, comprehensive, and symmetric way of integrating different disciplinary perspectives. While the boundary object approach enables us to develop a shared problem framing underpinned by a theoretical framework, the Constellation Analysis provides the methodical basis for an iterative and self-reflective process of integrating research insights and thus mapping the constellation defined by the boundary object. Additionally, this particular framework offers an approach which can, through anchoring within the core concepts, "result in decisive progress for discipline-specific knowledge" [9] (p. 276).

\section{Boundary Object in DynaMo: 'Sustainable Transformation of Urban Passenger Mobility'}

When the junior research group DynaMo was conceptualized to investigate 'Mobility-Energy Dynamics in Urban Areas', the question arose of how to integrate the knowledge and perspectives of researchers from the different disciplines involved. Even though political science and sociology share a wide set of theoretical and methodical concepts and tools, looming differences with regard to the usage of terms and the disciplines' seminal works remained an obstacle. What, for instance, would be investigated when speaking of mobility in the context of the research group? Would the focus encompass a wide perspective including social and global mobility, as common among many sociologists (see for instance [24])? Or would mobility be used in a narrower, technical sense, describing the physical movement from one place to the other as well as the social and political prerequisites for and consequences of this movement (see for instance [25])? An answer to these and further questions proved to be necessary to account for different paradigms and narratives, even in disciplines as close as political science and sociology, as a prerequisite to working toward the same ends while using diverse methods and theoretical frameworks. A good starting point for building this joint basis was, as described above, establishing a boundary object. In the following section we will approach this process, by first describing the way up to DynaMo's boundary object. Then, we will introduce our extension of core concepts, developed to improve and structure knowledge integration within an interdisciplinary research group.

\subsection{Towards the Boundary Object of 'Sustainable Transformation of Urban Passenger Mobility'}

DynaMo's boundary object was developed over the course of many project meetings and through a facilitated transdisciplinarity workshop that helped the group to identify common ground between the involved researchers [1] (p. 11 f.). Since one of the junior research group's overall objectives is to do both problem-oriented research, of which practical recommendations can be derived, and disciplinary basic research, in the form of $\mathrm{PhD}$ projects, the process of developing the boundary object was quite time-consuming and challenging. Additionally, the boundary object had to be sufficiently open into two directions: (a) openness in terms of problem orientation, which means that it should be close enough to real-world issues in the mobility sector so that it is accessible to the needs and interests of non-academic actors and (b) openness in terms of disciplinary compatibility, which means that 
all involved researchers should be able to specify discipline-relevant research questions which at the same time also relate to the boundary object. Considering the scope of the research group as well as the interests of the then-involved researchers, the group eventually agreed on the boundary object 'sustainable transformation of urban passenger mobility'.

Though interdisciplinary accessible, the elements of this boundary object were narrowed as follows: Sustainable transformation (in an urban context) refers to the purposeful change of urban systems towards sustainability in an ecological, economic, and social dimension. Urban passenger mobility, meanwhile, describes individuals' urge to move from one place to another, which is evoked by individual needs and is spatially and temporally fulfilled within urban transport systems (for these definitions again see [1] (p. 12)).

These definitions further confine the DynaMo group's scope of research in three different ways. The research focusses (a) on sustainable transformations of mobility instead of pathways in a more general sense, (b) on urban contexts specifically, and (c) on the mobility of persons and not, for instance, on the mobility of goods(again see [1]). In the first place, those remained the main confinements of DynaMo's boundary object. To keep it that broad was a willing decision to be connectable to a wide range of practical questions and actors in a transdisciplinary fashion. In the regularly held stakeholder workshops, practitioners did welcome the broad perspective of the boundary object, as they were able to relate to it from their own background. Yet, the broadness came with potential costs for the analytical value of the boundary object, that was addressed by further differentiating and enriching it during the emerging working progress of DynaMo.

Before explaining this development further, some conclusions on the boundary object's 'fitness' seem appropriate to evaluate the results of this essential step for the work of DynaMo. 'Sustainable transformation of urban passenger mobility' provides a suitable boundary object in the context of DynaMo, as it incorporates the three crucial features of a boundary object outlined above:

- Interpretative flexibility: While, as explained above, DynaMo's boundary object is narrowed to certain specifically defined elements, the elements are open to interpretation by different theoretical and disciplinary approaches, whereby the different researchers involved all speak to the elements 'in their language'. Thus, the different elements in themselves, as well as the boundary object as a whole, can be taken up and applied to different projects and interests situated in different disciplines.

- Organizational structure: By focusing on the elements of the boundary object applied in DynaMo, it was possible to chisel out common reference points, a space for translation, not only from a scientific view but also from a practical perspective: Beyond their meaning in scientific discourses and debates, the terms used in the boundary object are also accessible, and thus, can be interpreted by practitioners in the fields of policy-making, administration, business, and civil society. This clearly fulfils the criterion of the boundary object as an object that people act towards and with, as it is applicable as an instrument in theoretical as well as in practical reflection.

- Dynamic between ill-structured and more tailored uses of the objects: Derived from these two prerequisites, the boundary object defined by DynaMo can become a tool in public as well as in scholarly debates, both of which are likely to further shape the boundary object. Through its resonance to both spheres, to more general references as well as to thorough theoretical reflections, the boundary object is maintained and further developed, as will become clearer in the following section.

Even though the boundary object developed for and within DynaMo seems to fulfil the basic criteria, the process of maintaining and elaborating on the boundary object are difficult yet necessary tasks required to keep the boundary object alive and 'in shape'. This is why, in the case of DynaMo, we decided to enrich the boundary object with core concepts. 


\subsection{Core Concepts in DynaMo-Further Operationalization of the Boundary Object}

Core concepts were developed to layout analytical dimensions and to differentiate between different perspectives represented in the boundary object. While, as argued above, the concept of a boundary object as such has gained some scholarly attention in the field of inter- and transdisciplinary research, the development of core concepts marks an extension to the already existing conceptualization. We define core concepts as vanishing points for the collaboration of different research strands that allow for a deeper analysis of a boundary object. In the example of DynaMo, these research strands are the different qualification projects assembled. Consequently, the core concepts also stem from the research interests of the group members and are more relevant for some qualification projects than for others. Nonetheless, the core concepts can be considered as connected-they speak to each other and, as we will show in due course, are interdependent. Once set up, their arrangement must be constantly evaluated such that the core concepts can be replaced as needed. Working with core concepts is therefore not a one-time effort at the beginning of a project, it is a continuous process throughout the collaboration.

For DynaMo, assembling the set of core concepts marked an important step subsequent to the formulation of the group's boundary object. Different concepts were collected, tested, and discussed. Disciplinary research approaches to these concepts were exchanged and mutually reviewed, as well as preeminent links of the concepts to questions of mobility systems and transitions. Six core concepts were originally agreed upon, based on the previous research and planned qualification projects of the DynaMo researchers [1] (p. 12) (see Table 1).

Table 1. Core concepts used by the DynaMo junior research group.

\begin{tabular}{|c|c|}
\hline Core Concept & Explication \\
\hline Governance & (Political) Steering processes with regard to mobility that take place in actor networks \\
\hline Participation & $\begin{array}{l}\text { Involvement of different actors in mobility-related knowledge creation, deliberative, } \\
\text { decision-making and implementation processes }\end{array}$ \\
\hline Digitalization & $\begin{array}{c}\text { Change of mobility ranges and practices through the digital connection of services, } \\
\text { users and structures }\end{array}$ \\
\hline Mobility practices & All human (non-)actions that are related to movement from one place to another \\
\hline Legitimacy & $\begin{array}{l}\text { State in which mobility-related situations and actions are considered as socially } \\
\text { acknowledged and justified }\end{array}$ \\
\hline Space & $\begin{array}{c}\text { Constellation of individuals and objects that can be described using geographic, } \\
\text { social and psychological sense-making heuristics }\end{array}$ \\
\hline
\end{tabular}

In the course of the project, the core concept of digitalization was excluded because it is arguably situated on a different level than the other concepts in the framework. More specifically, it is embedded in other concepts. We conceded that a discussion of digitalization was inevitable while working within other core concepts, as for instance space or participation, both of which are subject to digitalization. Likewise, digitalization seemed not to have much analytical value on its own, independent of the other concepts, for the discussion of the individual qualification projects within the DynaMo research group. Simultaneously, another core concept was added to DynaMo's constellation [26] (pp. 17,27) (see Table 2).

Table 2. Reformulation of the DynaMo core concept constellation.

\begin{tabular}{cc}
\hline Core Concept & Explication \\
\hline Power & $\begin{array}{c}\text { Multi-layered concept that accesses the "(in)capacity of actors to mobilize } \\
\text { resources and institutions to reach a goal” [27] through a structural, instrumental } \\
\text { or discursive lens }\end{array}$ \\
\hline
\end{tabular}


Unlike digitalization, power seemed to be an important perspective relevant to several of the research group's qualification projects while at the same time being efficacious on its own as a concept. Within different dimensions of power (see for instance [28]), unequal distributions of that power can cause social and cultural lock-ins hindering the progress of mobility transitions. To solve these complex problems, it seems, therefore, necessary to address and eventually deconstruct these power relations.

At the same time, power also provides insights into the potential conflicts that needed to be addressed during the compilation of the core concepts. For instance, in some scholarly traditions, the term of 'regime' is exclusively used to describe a hegemonic block of power, that hinders progress in the mobility sector, most noteworthy the regime of the automobile industry [29,30]. Others have sought to use the term to describe counter-hegemonic empowerment through which niches of transformation might themselves become a more powerful "niche regime" [31] challenging the social status quo [27]. Working with the core concept of power, therefore, involved discussions about how to understand and use the term and adherent concepts in the light of its role in transformation processes. Similar questions also played a role while defining the other core concepts (see again Table 1). As we will argue in Section 4, solving these questions is a highly subjective and continuous process, every research group using this framework would be confronted with.

The core concepts were formulated to be as generally understandable and as comprehensive as possible, in order to be accessible for researchers rooted in different disciplines as well as for practitioners and stakeholders. This enables communication about these core concepts without excluding some actors. Of course, since these core concepts represent - at least partly - common concepts which are defined in many different and sometimes even mutually excluding ways, they always have to be further specified for disciplinary argumentation and research.

Chiseling out and confining these core concepts was a consuming task that involved above all discussions between the members of the group. Given the disciplinary proximity of political science and sociology, relatively little fundamental disagreements arose in this exchange. Also, all researchers involved still face the task to redefine and adapt the core concepts central to their own qualification projects and disciplinary backgrounds. Nonetheless, it became obvious that for the joint work within the group the core concepts would need further knowledge building among the researchers involved to enable a joint understanding and address potentially conflicting definitions. To shed light on this, we consider it helpful to situate the core concepts within the differentiation between three knowledge forms common in the field of transdisciplinary research: systems knowledge (i.e., knowledge about the genesis and further development of a given empirical problem), orientation knowledge (i.e., knowledge about desired goals), and transformation knowledge (i.e., knowledge about how to tackle a given problem and transform it into a desired direction) [32] (see Figure 1). To facilitate successful analysis of empirical problems, this differentiation suggests, that the different knowledge forms need to be integrated, that means, they need to be confronted with each other and enrich each other mutually. Put differently, without concise knowledge of normative orientation and an application to transformation contexts, systems knowledge is of limited value for practice-orientated research.

In our framework, the core concepts themselves can be located in the realm of systems knowledge: They describe dimensions of mobility that are observable and, at the same time, are pivotal for successful mobility transitions. While it is on the level of systems knowledge that the concepts themselves are brought into a constellation and are enriched with the disciplinary knowledge of the researchers involved, it is through the level of orientation knowledge that they are filled with meaning related to the boundary object. Thereby, the core concepts allow for deconstructing and accessing different dimensions of the boundary object. In the particular case of 'sustainable transformation of urban passenger mobility', the concepts, for instance, help us to gain a better understanding of the complexity of the term sustainability, which represents the normative element of DynaMo's boundary object. Through the careful and multi-faceted view enabled by the core concepts, we can analyze sustainability in a multi-dimensional and 'strong' way, integrating the realms of economic, social, and ecological sustainability while prioritizing the latter. Strong sustainability, in contrast to weak 
sustainability, prioritizes aspects of ecological sustainability above economic and social sustainability, both of which are entirely relating to a functioning environment. By applying a strong sustainability framework, urgency is attributed to the matter under investigation in terms of a functioning system. In the case of mobility transitions, a strong sustainability perspective means, that the transformative, disruptive character of the transition is needed because of the urgent ecological consequences caused by predominant mobility systems and practices (for a more coherent definition see $[33,34]$ ). Alas, the level of orientation knowledge specifies towards what end sustainable transition ought to evolve and establishes a normative focus for the joint work within the research group.

Via this reaffirmation, the core concepts can be used on the level of transformative knowledge to identify challenges and pathways in case-related transition processes. In other words, at this level, we can use the core concepts to decipher the idea of sustainability related to distinct (policy) measures. In the confrontation with the two other knowledge forms, the core concepts can be tested for their usefulness as tools for empirical, interdisciplinary research. Only by performing this 'journey' of integrating the three different forms of knowledge, their meaning can be applied, thus becoming what Jennifer Milliken (and others) has described as "meaning-in-use" [35] (p. 231). From this perspective, discourses on the core concepts with the lens of strong sustainability are perceived as "structures that are actualized on their regular use by people of discursively ordered relationships in 'ready-at-hand language practices' or other modes of signification" (ibid., emphasis in original). Those structures then become productive in the realm of transformation knowledge within spaces, in this case cities.

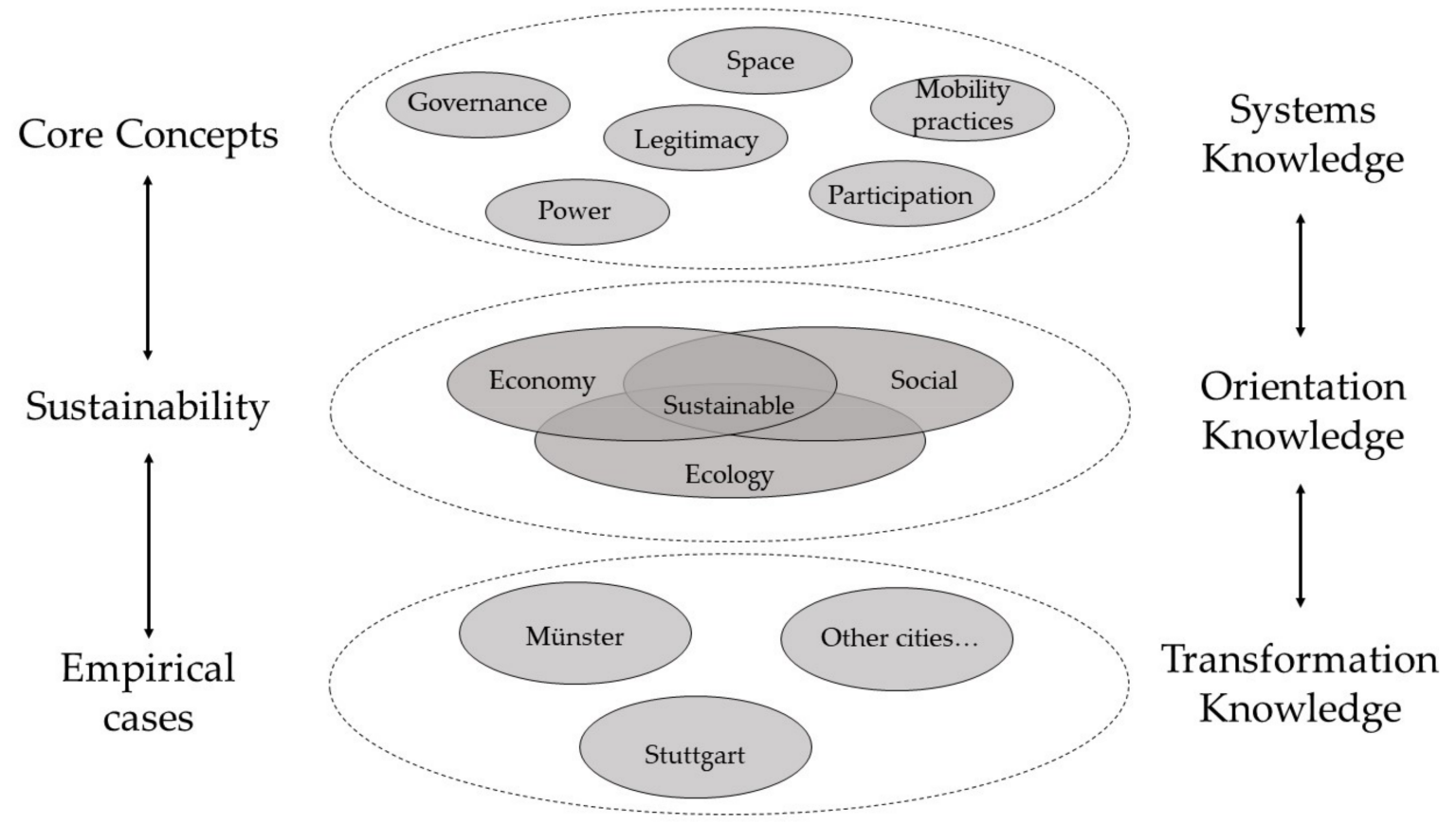

Figure 1. Conceptual framework of DynaMo (adapted from [1] (p. 13)).

\subsection{Working with a Boundary Object and Core Concepts}

The above-described process has inter alia been used in DynaMo's second working paper (Werkstattbericht II) to analyze measures of mobility transitions in the German cities of Stuttgart and Münster [26]. The DynaMo working papers are thought of as an integral part of the research group's work, aiming at documenting the working progress of the group. This possibility of documentation and reflection provides an important space to advance and reconsider the boundary object and the core concepts. While the first DynaMo working paper (Werkstattbericht I, [1]) aimed to give insight into the constitutive work in the launching phase of DynaMo, in the context of the second working paper, the core concepts proved to be extremely helpful in outlining conflicts and perspectives towards 
transformational (policy) measures because, on the one hand, using the core concepts limited the scope of analysis to dimensions all involved researchers had previously agreed on. On the other hand, it linked the analysis to relatively distinctive categories that are also accessible for practitioners who are evaluating and improving these or similar measures.

One example from that contribution is the core concept of participation, which can serve as a good illustration of our approach. Firstly, we laid out our systematization of the concept of participation in an interdisciplinary manner. The description of the core concept underwent a 'review' process within the research group, through which we tested the connectivity of the conceptualization to all disciplines involved. Secondly, we then applied the concept to the two cases in question, Münster and Stuttgart. From both cases, we chose two policy measures for closer analysis: fast lane cycle tracks (Münster) and driving bans (Stuttgart). The wide, interdisciplinary understanding of participation allowed us to access processes in both cities. Yet, it also made it possible to shed a light on challenges and possible shortcomings of the measures in question. While both measures involved, to some extent, top-down forms of participation, it became clear that a lack of bottom-up participation could threaten the acceptability of the these measures. Likewise, the broad 'supra-disciplinary' understanding of participation widened the scope of what was considered to be participation. For instance, we considered lawsuits against the local government, as in the Stuttgart case, as forms of participation, as were forms of protest against (or for) the measures in question. The consultation of different theoretical approaches to 'participation' is a good example of potential conflicts and mutual learning through exchange and knowledge integration. Not to understand participation solely in a formalized way, but also including protest as a performative act to make something visible and recognizable [36], for instance snarls institutional approaches in political science. Yet, the joint work on the term made it possible to agree on the value of understanding protest as participation given the integration of orientation and transformation knowledge. If, for example, from a strong sustainability perspective, protest is the only way to make a 'claim' of an ecological infraction visible, it is necessary to raise the understanding of the problem within a certain case-with the latter referring to transformation knowledge (see Maarten Hajer's still seminal work on discourses in sustainability research [37]). Obviously, progress and, though not necessarily, agreement on the meaning of the core concepts related to a certain meaning in a certain case, can often only be decided upon during the joint working process and the adherent integration of knowledge. Furthermore, the two forms of participation, one formal and one informal, relate to the core concept of legitimacy, as this is what is questioned through acts of participation. Consequently, it became clear that the core concepts speak to each other and, thus, that they help to keep the boundary object dynamically 'in motion' and developing (see for this paragraph [26] (pp. 19 f.).

Notably, in this latter example, we integrated the work with the boundary object and its adherent core concepts right from the beginning. However, beyond using the boundary object in this way, DynaMo also intends to use the boundary concept to further integrate the knowledge created within the different qualification projects that are part of the group. Instead of working on a joint subject, the boundary object, as explained earlier, is used here as a bridge or a channel of exchange between different subjects. With the help of the boundary object and the core concepts, the different projects will eventually speak to each other and, within this conversation, uncover joint understandings and generate further new knowledge. To set up these channels, the projects at hand need to be brought into a constellation that sets out which core concepts are predominant in which projects and, thus, which core concepts function as a channel between which different projects. To achieve this, the method of Constellation Analysis as described in the previous section seems to be a promising approach.

\section{4. 'Back \& Forth' - Constellation Analysis for 'Sustainable Transformation of Urban Passenger Mobility'}

As modus to strategically integrate knowledge in the context of interdisciplinary research, Constellation Analysis takes the different participating perspectives on a research object into account. 
To briefly recount our remarks in Section 2.2, Constellation Analysis has three basic steps: The first step is 'mapping the constellation'. It involves identifying substantial elements (actors, technical, symbolic, and natural elements), arranging these elements from those that are central to those that are more peripheral, and describing relations between those elements. The second step clarifies how the constellation works and seeks to 'uncover the logical core' by identifying the functional principles and the characteristics of elements (e.g., the dominance of specific actors, power constellations, etc.). The third step aims to 'consider changes' that have occurred in the past or will affect the constellation in the future (e.g., regulation, political orders, etc.) [9] (pp. 263-265). In other words, Constellation Analysis can be used to answer three basic questions: What is the constellation about, how does it work, and how did it develop, respectively how is it going to develop in the future?

In the junior researcher group DynaMo, the members' qualification is an integral part, the $\mathrm{PhD}$ projects are especially important contributions to the overall development of the collaboration. Therefore, the continuous application of Constellation Analysis is a way of integrating new insights and developments from each individual qualification project into the overall project, and vice versa, in order to ensure interdisciplinary coherence. Consequently, the boundary object and the individual $\mathrm{PhD}$ projects stand in an ongoing dialog with each other facilitated via personal meetings, conference calls, and also via feedback on written words. This reciprocal relationship between boundary object and PhD projects can be paraphrased with the term 'back and forth' and operates with the modi of Constellation Analysis. The pendulum moment consists of two research processes in the context of DynaMo which are systematically linked by means of Constellation Analysis: (a) the consolidation of the boundary object through joint development of the research agenda of the overall project team (including practitioners, stakeholders, mentors, and a scientific advisory board) and (b) the rather disciplinary production of new knowledge through the individual qualification projects. At the same time, the intermediation between the group and the individual projects mitigates potentially conflict-laden processes. Of course, reaching an agreement on the development of the boundary object does not necessarily take place without confrontational discussions. Methodological concerns, disciplinary socializations, other research interests, and personal worldviews may lead to hardened fronts in dialogs. However, the sovereignty to configure the individual qualification project based on own ideas disencumbers conflict-laden situations. The pendulum movement between phases of interdisciplinary work towards the boundary object and phases of disciplinary work on the individual $\mathrm{PhD}$ projects is illustrated in the figure below (see Figure 2).

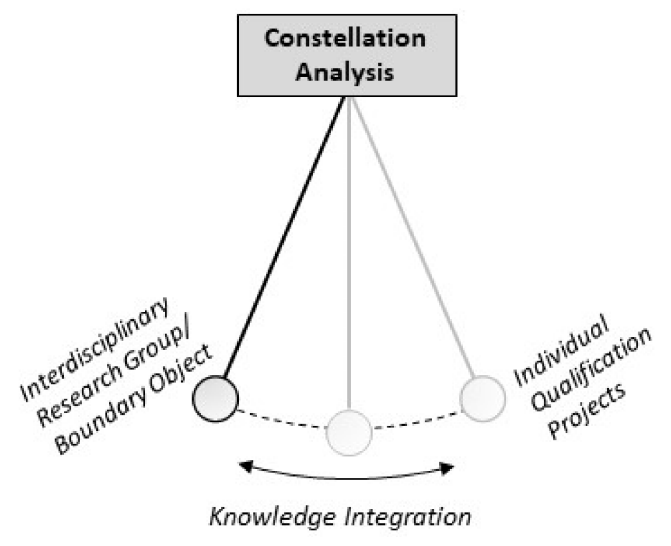

Figure 2. 'Back \& Forth': knowledge integration within DynaMo.

The core concepts (see Figure 1: governance, power, legitimacy, etc.) which describe and specify the boundary object serve as reference points for the processes of knowledge integration. As 'communication enablers', they help to stimulate discussions while, at the same, they add an analytical dimension to empirical occasions, everyday-life observations, or discursive events. By this 
means, the core concepts allow for a smooth transition from disciplinary theorizing and reasoning into interdisciplinary communication and knowledge integration.

In order to practically illustrate the application of Constellation Analysis in DynaMo, we exemplify the interaction between boundary object and qualification projects by using the questions introduced by Constellation Analysis: What is the constellation about, how does it work, and how is it going to/did it develop. It is important to note that these questions are already applications of Constellation Analysis since they represent the understanding of Constellation Analysis in our project. Furthermore, as we will see, each question does not exclusively belong to one 'round of application'. Instead, there are overlaps between the questions, depending on the (disciplinary) stance one takes. Furthermore, the interaction does not start in a vacuum. On the contrary, each member of the group brings in his or her previous knowledge, including scientific education and examination as well as knowledge on core literature in sustainable mobility - recently reviewed for the preparation of research proposals for the dissertations.

What is the constellation about-developing the boundary object: Together with the consolidation of the junior researcher group DynaMo, we developed the boundary object. The process took around eight months and encompassed personal meetings as well as telephone conferences and pictured documentations. In a first step and with the topic of 'Mobility-Energy Dynamics in Urban Areas' in mind, we identified actors, technical elements, symbolic elements, and natural elements on different colored paper and collected them. From this activity, we got a huge amount (!) of cards that we structured in the next step. We arranged them to be located at the center and further out towards the periphery, which helped us to identify the most important elements of the constellation. At the same time, elements which were very similar were brought together. After structuring and reducing the number of cards, we mapped the relations between the different elements. We then identified relations which were most important in the context of the current debate and highlighted them together with the connected elements. This way, we were able to 'draw boundaries' and to identify more clearly our boundary object 'sustainable transformation of urban passenger mobility'.

How does the constellation work - a discussion of sustainable urban mobility measures with the help of core concepts: To learn more about the way the constellation works, Constellation Analysis aims to identify functional principles and characteristics of the elements. Therefore, in our second working paper (Werkstattbericht II [26]), we identified and discussed two measures which are important for our cases Münster and Stuttgart (implementing fast lane cycle tracks in Münster and diesel driving bans in Stuttgart) in the context of each core concept. In doing so, we updated the core concepts (which specify the boundary object) and at the same time discussed specific operational logics within the boundary object. In light of Constellation Analysis, this step has brought three related impulses for the overall development of the project: First, it helped us to also work out the relations among our core concepts more precisely, second, it shed light on how the different elements of the constellation work together in practice, and, third, the group discussed intensively how exactly the core concepts fit the empirical phenomenon. Since the core concepts are closely connected with the theoretical approaches feedback on theory-practice-transfer was provided.

How is the constellation going to develop-collaboration with colleagues and partners: Constellation Analysis also refers to the way in which social, technical, or policy change will affect the constellation in the future or has influenced the constellation in the past. We have chosen the future-oriented version to assess future developments. To elaborate on the far-reaching and complex questions, we asked for input from practitioners during a the regularly held stakeholder workshops and integrated their insights on possible future developments. Thus, practitioners assist to carry out the knowledge integration with feedbacks, evaluations, and prospects in their area of expertise (for example political or technological developments). In the stakeholder workshops, we worked together in small groups using guiding questions in order to identify key developments and discuss them.

The brief illustration with the aforementioned examples shows one specific way of using Constellation Analysis. The applications of Constellation Analysis with the help of guiding questions (What is the constellation about, how does it work, and how did it develop, respectively how is it 
going to develop in the future?) has been a key factor for us to access the empirical phenomena with a methodological lens. However, the illustrations also clarify that the research context (e.g., the composition of the team) influences the way of application decisively. In this perspective, mapping the constellation turns out to be a highly constitutive act: drawing boundaries becomes a decision-making process on elements concerning relevance, rank, and level of specificity.

\section{Discussion and Conclusions}

In this paper, we introduced and applied a systematic framework for integrating interdisciplinary knowledge in transdisciplinary research projects. As described in the sections above, there is an intense debate on interdisciplinary knowledge integration, as inter- and transdisciplinary research has become highly relevant due to the growing complexity of socio-ecological issues modern societies face. Being confronted with the challenges of knowledge integration, we sought out helpful concepts and approaches for interdisciplinary knowledge integration (in the field of sustainable urban mobility transitions). To integrate different disciplinary perspectives in a systematic manner, we innovatively combined Susan Star's and James Griesemer's boundary object concept with Constellation Analysis and developed what we call core concepts as communication enablers between the boundary object and individual qualification projects. By treating social, biophysical, and technical aspects equally, we aim to deepen the understanding of socio-technical phenomena and to offer a self-reflective tool for structuring the process of interdisciplinary knowledge integration.

By defining the core concepts, we managed to agree on one language bridging the respective disciplines. Researchers that joint our group at a later stage have described the concepts as very helpful for integrating themselves into the work of the group. Moreover, with the help of the Constellation Analysis, we started a structured exchange and were able to put the core concepts and our qualification projects in relation to each other. Although this structured exchange was not always free of conflict, it had the following advantages: The exchange enabled a broadening of each researcher's horizon, raised awareness for other topics in the field of urban mobility, and encouraged each of us to think outside its disciplinary box. Additionally, by getting to know other approaches, we recognized our own 'blind spots'. Therefore, the exchange helped to sharpen the own research approach as well as the own researcher personality.

Apart from the internal learning processes, the contribution of our combined framework is twofold: It offers both conceptual and practical orientation for interdisciplinary knowledge integration.

First, our approach provides a new conceptual tool in the 'toolkit' of interdisciplinary research. Both inter- and transdisciplinary research are on a constant search for effective tools and methods: Relevant concepts and methods have been developed and systematized. One example of a collection of inter- and transdisciplinary tools is Gabriele Bammer's "Toolkits for Transdisciplinarity" [35]. However, the boundary object as it is used in our research group—operationalized by the core concepts and the Constellation Analysis-is not part of Bammer's toolkit and to our knowledge also not included in any other systematization of concepts and methods for inter- and transdisciplinary research. With our approach, we thus enrich the 'toolkit for co-producing knowledge' by combining the boundary object concept, core concepts, and Constellation Analysis. By explicitly addressing one central problem of interdisciplinarity - knowledge integration - the framework can be understood as a tool that promotes understanding and learning across disciplines and, thus, approaches one of the central obstacles of interdisciplinary collaboration.

However, all of the options and methods available require the actors within an interdisciplinary research group to have practical knowledge of how to apply them in order to make sure their group chooses an appropriate approach for knowledge integration according to their specific problems, group dynamics, and contexts. Thus, our second contribution is that through the empirical illustration of the framework along with the boundary object 'sustainable transformation of urban passenger mobility', we offer practical knowledge on how to apply our proposed tool. In our example, we initiated a broader dialogue on the application of concepts. Overall though, we contend that learning in interdisciplinary research and expanding methodological knowledge depends on testing methods for specific cases. 
Although the framework focuses on interdisciplinary knowledge integration, it represents an innovative conceptual approach that has high transfer potential, in that it is also applicable to transdisciplinary research and exchanges with practitioners and stakeholders. In the particular case of the DynaMo research group, the core concepts (participation, legitimacy, space, governance, mobility practices, and power) offer opportunities for including non-academic perspectives. As communication enablers, they reduce the complexity of theoretical approaches and can be connected easily with empirical phenomena as well as everyday observations. Additionally, core concepts travel among the different forms of knowledge (systems, orientation, transformation) and have thus become essential for knowledge integration. Insofar, the framework can be seen as smoothing the way towards transdisciplinary research on issues beyond the sustainable transitions of mobility practices and systems alone.

As mentioned above, our article represents one specific way of using the boundary object concept and Constellation Analysis that is highly influenced by the research context (i.e., involved researchers and societal developments). Therefore, our framework is never complete and in constant flux. The dynamics resulting from that unfinished character facilitate the necessary flexibility for ongoing developments of the constellation and the individual qualification projects. Additionally, the open-ended process stands for persistent methodological work and reflection processes. In this sense, the paper becomes an additional step towards consolidating and advancing our interdisciplinary approach.

Nevertheless, our approach faces some limitations. To begin with, of course, a well-thought-out framework on knowledge integration does not, by itself, solve a societal challenge like the transition towards more sustainable urban mobility. Moreover, interdisciplinary knowledge integration is a time-consuming process. Methods for cross-boundary communication and collaborative research need to be trained and applied to enable people from different disciplines to communicate with and understand each other. Still, integrating disciplines requires resolving conflicts between research paradigms and discipline-specific methods. Researchers are required to learn and "relearn across disciplines" [38] (p. 9), which requires a certain attitude (openness, interest, curiosity), considerable time, and effort. These time-consuming processes potentially conflict with the dynamics of pressing problems and project time frames. Furthermore, especially for junior researchers it is a challenge to become deeply rooted within a 'home discipline' and at the same time get an overview of interdisciplinary approaches (more and more considered to be a necessary asset for a successful academic career). Likewise, the logic of academic advancement, funding, and publishing seems to be challenging in a similar manner and potentially conflictive with ambitious interdisciplinary efforts [2] (p. 380 f.), [39].

Although the DynaMo group is interdisciplinary, it is bounded by a social science paradigm. Thus, as the core concepts were developed by researchers from different social science fields, they primarily cover the social science perspective, technology development or impact assessment stands in the background. Accordingly, we are regularly in exchange with researchers from other disciplines, such as geography, engineering, law and so forth who thereby also influence our constellation. However, we are, at the same time, well aware that interdisciplinary research cooperation will not (and will never) be able to cover all disciplines and that the disciplinary orientation of the framework's operationalization will be molded by the researchers' disciplines. Those responsible for developing interdisciplinary research groups or networks need to identify and integrate the disciplines which are relevant for approaching research fields characterized by uncertainty, ambiguity, and opposing stakeholder perspectives.

In conclusion, this paper has provided a distinctive conceptual and practical contribution to debates on interdisciplinary knowledge integration exemplified by the case of interdisciplinary research on urban mobility. By lining out and illustrating the synthesis of the boundary object concept and Constellation Analysis, we aimed to make the framework easily accessible to others. We hope this paper encourages further applications and adaptions of the framework in different research contexts. This can be a fruitful way of continuously reflecting on and advancing methods for inter- and transdisciplinary research that strives to provide knowledge for dealing with complex socio-ecological problems. 
Author Contributions: All authors contributed equally. Conceptualization, B.F., N.S., N.F., A.-K.G., A.G., M.L., and M.S.; writing—original draft, B.F., N.S., N.F., A.-K.G., A.G., M.L., and M.S; writing—review \& editing, B.F., N.S., N.F., A.-K.G., A.G., M.L., and M.S.

Funding: The research was funded by the German Federal Ministry of Education and Research (Bundesministerium für Bildung und Forschung, BMBF) within the funding program Social-Ecological Research (Grant No. 01UU1605).

Acknowledgments: We appreciate the editing work of Celeste Brennecka. Moreover, we want to thank the editors of the special issue and the anonymous reviewers for their valuable comments which helped to substantially improve the paper.

Conflicts of Interest: The authors declare no conflict of interest.

\section{References}

1. Graf, A.; Sonnberger, M.; Alcántara, S.; Fanderl, N.; Feldwieser, M.; Schick, C. Wissensintegration. Eine interund transdisziplinäre Perspektive auf die nachhaltige Gestaltung von Personenmobilität in urbanen Räumen; Erster DynaMo-Werkstattbericht: Münster, Germany, 2018.

2. Jaeger-Erben, M.; Kramm, J.; Sonnberger, M.; Völker, C.; Albert, C.; Graf, A.; Hermans, K.; Lange, S.; Santarius, T.; Schröter, B.; et al. Building Capacities for Transdisciplinary Research: Challenges and Recommendations for Early-Career Researchers. GAIA Ecol. Perspect. Sci. Soc. 2018, 27, 379-386. [CrossRef]

3. Jahn, T.; Bergmann, M.; Keil, F. Transdisciplinarity: Between Mainstreaming and Marginalization. Ecol. Econ. 2012, 79, 1-10. [CrossRef]

4. Truffer, B. Wissensintegration in transdisziplinären Projekten: Flexibles Rollenverständnis als Schlüsselkompetenz für das Schnittstellenmanagement. GAIA Ecol. Perspect. Sci. Soc. 2007, 16, 41-45. [CrossRef]

5. Godemann, J.; Michelsen, G. Transdisziplinäre Integration in der Universität. In Transdisziplinäre Forschung: Integrative Forschungsprozesse verstehen und bewerten; Bergmann, M., Schramm, E., Eds.; Campus Verlag: New York, NY, USA; Frankfurt am Main, Germany, 2008; ISBN 9783593388465.

6. Thompson Klein, J. Integration in der inter- und transdisziplinären Forschung. In Transdisziplinäre Forschung: Integrative Forschungsprozesse verstehen und bewerten; Bergmann, M., Schramm, E., Eds.; Campus Verlag: Frankfurt am Main, Germany, 2008; pp. 93-116.

7. Research for Sustainable Development (FONA). Junior Research Groups Social-ecological Research. Available online: https://www.fona.de/en/measures/funding-measures/junior-research-groups-socialecological-research.php (accessed on 15 July 2019).

8. Star, S.L.; Griesemer, J.R. Institutional Ecology, "Translations" and Boundary Objects: Amateurs and Professionals in Berkeley's Museum of Vertebrate Zoology, 1907-39. Soc. Stud. Sci. 1989, 19, 387-420. [CrossRef]

9. Ohlhorst, D.; Schön, S. Constellation Analysis as a Means of Interdisciplinary Innovation Research - Theory Formation From the Bottom Up. Hist. Soc. Res. 2015, 40, 258-278. [CrossRef]

10. Star, S.L. This is Not a Boundary Object: Reflections on the Origin of a Concept. Sci. Technol. Human Values 2010, 35, 601-617. [CrossRef]

11. Trompette, P.; Vinck, D. Revisiting the Notion of Boundary Object. Revue Anthropol. Connaiss. $2009,3$. [CrossRef]

12. Metze, T. Fracking the Debate: Frame Shifts and Boundary Work in Dutch Decision Making on Shale Gas. J. Environ. Policy Plan. 2017, 19, 35-52. [CrossRef]

13. Carlile, P.R. A Pragmatic View of Knowledge and Boundaries: Boundary Objects in New Product Development. Organization Science 2002, 13, 442-455. [CrossRef]

14. Sundberg, M. Parameterizations as Boundary Objects on the Climate Arena. Soc. Stud. Sci. 2007, 37, 473-488. [CrossRef]

15. Bergmann, M.; Jahn, T.; Knobloch, T.; Krohn, W.; Pohl, C.; Schramm, E. Methods for Transdisciplinary Research. A Primer for Practice; Campus: Frankfurt, Germany, 2012.

16. Lainer-Vos, D. Boundary Objects, Zones of Indeterminacy, and the Formation of Irish and Jewish Transnational Socio-Financial Networks. Organ. Stud. 2013, 34, 515-532. [CrossRef]

17. Berker, T.; Kvellheim, A.K. Boundary Objects as Facilitators in Sustainable Building Research. Sci. Public Policy 2018, 45, 202-210. [CrossRef]

18. Wenger, E. Communities of Practice and Social Learning Systems. Organization 2000, 7, 225-246. [CrossRef] 
19. Schön, S.; Kruse, S.; Meister, M.; Nölting, B.; Ohlhorst, D. Handbuch Konstellationsanalyse. Ein interdisziplinäres Brückenkonzept für die Nachhaltigkeits-, Technik- und Innovationsforschung; oekom: München, Germany, 2007.

20. Schäfer, M.; Ohlhorst, D.; Schön, S.; Kruse, S. Science for the Future: Challenges and Methods for Transdisciplinary Sustainability Research. Afr. J. Sci. Technol. Innov. Dev. 2010, 2, 114-137.

21. Latour, B. Science in Action. How to Follow Scientists and Engineers Through Society; Harvard University Press: Cambridge, MA, USA, 1987.

22. Latour, B. Reassembling the Social. An Introduction to Actor-Network-Theory; Oxford University Press: Oxford, UK, 2005.

23. Lang, D.J.; Wiek, A.; Bergmann, M.; Stauffacher, M.; Martens, P.; Moll, P.; Swilling, M.; Thomas, C.J. Transdisciplinary research in sustainability science: Practice, principles, and challenges. Sustain. Sci. 2012, 7, 25-43. [CrossRef]

24. Urry, J. Mobilities; Reprint; Polity Press: Cambridge, UK, 2012; ISBN 978-0745634197.

25. Banister, D. Unsustainable Transport. City Transport in the New Century; Routledge: London, UK; New York, NY, USA, 2005.

26. Sonnberger, M.; Graf, A.; Fanderl, N.; Feldhoff, B.; Gahle, A.-K.; Leger, M.; Stockmann, N. Wissensanwendung. Eine konzeptionelle Betrachtung von Maßnahmen zur Gestaltung urbaner Personenmobilität; Zweiter DynaMo-Werkstattbericht: Münster, Germany, 2019.

27. Avelino, F. Power in Sustainability Transitions: Analysing Power and (Dis)Empowerment in Transformative Change towards sustainability. Env. Pol. Gov. 2017, 27, 505-520. [CrossRef]

28. Lukes, S. Power. A Radical View; Palgrave MacMillan: Houndmills, UK, 2005.

29. Geels, F.W. Regime Resistance against Low-Carbon Transitions: Introducing Politics and Power into the Multi-Level Perspective. Theory Cult. Soc. 2014, 31, 21-40. [CrossRef]

30. Paterson, M. Automobile Politics. Ecology and Cultural Political Economy; Cambridge University Press: Cambridge, UK, 2007; ISBN 9780521691307.

31. De Haan, J.; Rotmans, J. Patterns in transitions: Understanding complex chains of change. Technol. Forecast. Soc. Change 2011, 78, 90-102. [CrossRef]

32. Pohl, C.; Hirsch Hadorn, G. Core Terms in Transdisciplinary Research. In Handbook of Transdisciplinary Research; Hirsch Hadorn, G., Hoffmann-Riem, H., Biber-Klemm, S., Grossenbacher-Mansuy, W., Jove, D., Pohl, C., Wiesmann, U., Zemp, E., Eds.; Springer: Dordrecht, The Netherlands, 2008.

33. Giddings, B.; Hopwood, B.; O'Brien, G. Environment, Economy and Society: Fitting them Together into Sustainable Development. Sust. Dev. 2002, 10, 187-196. [CrossRef]

34. Lorek, S.; Fuchs, D. Strong sustainable consumption governance - precondition for a degrowth path? J. Clean. Prod. 2013, 38, 36-43. [CrossRef]

35. Milliken, J. The Study of Discourse in International Relations. Eur. J. Int. Relat. 1999, 5, 225-254. [CrossRef]

36. Butler, J. Notes Toward a Performative Theory of Assembly; First Harvard University Press paperback edition; Harvard University Press: Cambridge, MA, USA; London, UK, 2018; ISBN 9780674983984.

37. Hajer, M.A. The Politics of Environmental Discourse. Ecological Modernization and the Policy Process; Clarendon Press: Oxford, UK; New York, NY, USA, 1995; ISBN 9780198293330.

38. Rhoten, D. A Multi-Method Analysis of the Social and Technical Conditions for Interdisciplinary Collaboration. Available online: https://s3.amazonaws.com/ssrc-cdn1/crmuploads/new_publication_3/ a-multi-method-analysis-of-the-social-and-technical-conditions-for-interdisciplinary-collaboration.pdf (accessed on 16 July 2019).

39. Rhoten, D.; Parker, A. Education. Risks and rewards of an interdisciplinary research path. Science 2004, 306, 2046. [CrossRef] [PubMed]

(C) 2019 by the authors. Licensee MDPI, Basel, Switzerland. This article is an open access article distributed under the terms and conditions of the Creative Commons Attribution (CC BY) license (http://creativecommons.org/licenses/by/4.0/). 